УДК 82I.I33.I

ББК $83.3(4 \Phi$ ра $)+83$
«ПЕРСИДСКИЕ ПИСЬМА» ДЕТЯМ:

К ИСТОРИИ ПЕРЕВОДОВ

Ш.-Л. МОНТЕСКЬЕ В РОССИИ

(C) 2019 г. Е.Н. Васильева

Санкт-Петербургский государственный универ-

ситет, Санкт-Петербург, Россия

Дата поступления статьи: 23 января 2019 г.

Дата публикации: 25 июня 2019 г.

DOI: IO.22455/2500-4247-2OI9-4-2-I28-I43

Аннотация: Предметом исследования в статье являются наиболее ранние из известных на сегодняшний день опубликованных переводов романа «Персидские письма» Ш.-Л. Монтескье на русский язык. Первые русские версии «Персидских писем» представляют собой любительские переводы отдельных фрагментов романа и помещены в сборники «Детское чтение» (I779) и «Избранное чтение» (I786), предназначенные для детской аудитории. В основу обоих переводов, выполненных соответственно Капитоном Бочарниковым и Иваном Чашниковым независимо друг от друга, положен один и тот же фрагмент романа - вставная новелла о Троглодитах, которая имеет ключевое значение в политической теории Монтескье: история о Троглодитах в притчевой форме обосновывает преимущества республиканского строя. В статье предлагается сопоставительный анализ оригинального текста и его двух переводов, который позволяет выявить наличие текста-посредника, использованного К. Бочарниковым: «Lectures pour les enfants» французского детского писателя Арно Беркена. Устанавливается также, что при относительной тождественности переводов оригиналу сами переводы не тождественны друг другу ни в композиционном, ни в художественном плане. При этом в обоих случаях реализуется основная переводческая задача: материал, извлеченный из произведения взрослой философской литературы, преподносится в адаптированном для детского восприятия формате нравоучительного наставления. Тем самым книги Бочарникова и Чашникова обнаруживают связь с традицией детской переводной литературы второй половины XVIII в.

Ключевые слова: Монтескье, «Персидские письма», перевод, детская литература, Беркен, Бочарников, Чашников.

Информация об авторе: Екатерина Николаевна Васильева - кандидат филологических наук, старший преподаватель, Санкт-Петербургский государственный университет, Университетская наб., д. II, I99034

г. Санкт-Петербург, Россия. ORCID ID: о0оо-о0о2-4859-1060

E-mail: katia_vasilyeva@mail.ru

Для цитирования: Васильева Е.Н. «Персидские письма» детям: к истории переводов

Ш.-Л. Монтескье в России // Studia Litterarum. 2019. Т. 4, № 2. С. I28-I43.

DOI: IO.22455/2500-4247-20I9-4-2-I28-I43 


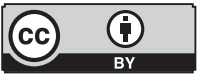

This is an open access article distributed under the Creative Commons Attribution 4.0 International (CC BY 4.0)

\section{PERSIAN LETTERS FOR CHILDREN: ON THE HISTORY OF MONTESQUIEU'S TRANSLATIONS IN RUSSIA}

\author{
(C) 2019. E.N. Vasilyeva \\ Saint-Petersburg State University, \\ Saint-Petersburg, Russia \\ Received: January 23, 2019 \\ Date of publication: June 25, 2019
}

Abstract: The article examines the earliest translations of Montesquieu's Persian Letters in the Russian language. The first Russian versions of the novel are fragmentary amateur translations included in such anthologies as Reading for Children (I779) and Selected Reading (I786) addressed to young readers. While realized independently of each other by Kapiton Bocharnikov and Ivan Chashnikov, these translations are based on the same fragment - the fable of the Troglodytes fable which is crucial in Montesquieu's political theory because it explains the advantages of Republic government. Comparing the original text and its translations has allowed me to reveal that Bocharnikov's translation relies on Lectures pour les enfants by a French children's author Arnaud Berquin as a mediator text. Another conclusion to be drawn is that while both translations relatively adequately correspond to the original text, they are different in terms of their literary value. At the same time, both translators fulfil their principal aim: withdrawn from the philosophical literature for adults, the Troglodytes fable is adopted for children as a didactic tale by both Bocharnikov and Chashnikov. This allows us to relate both translations to the tradition of translating children's literature in the second half of the $18^{\text {th }}$ century.

Keywords: Montesquieu, Persian Letters, translation, literature for children, Berquin, Bocharnikov, Chashnikov.

Information about the author: Ekaterina N. Vasilyeva, PhD in Philology, Assistant Professor, Saint-Petersburg State University, II Universitetskaya Emb., I99034 St. Petersburg, Russia. ORCID ID: 0000-0002-4859-1060

E-mail: katia_vasilyeva@mail.ru

For citation: Vasilyeva E.N. Persian Letters for Children: On the History of Montesquieu's Translations in Russia. Studia Litterarum, 2019, vol. 4, no 2, pp. I28-I43.

(In Russ.) DOI: IO.22455/2500-4247-20I9-4-2-I28-I43 
На протяжении XVIII столетия роман «Персидские письма» становился объектом внимания русских переводчиков чаще, чем остальные сочинения Монтескье, в том числе и программный трактат «О духе законов». Однако впервые полная печатная версия романа на русском языке, выполненная переводчиком Федором Поспеловым, появится лишь в I789 г., почти через семьдесят лет после выхода романа на родине [3]. В годы, предшествовавшие появлению первого полного русского перевода, роман печатался фрагментами в различных небольших изданиях. На сегодняшний день известно по меньшей мере три петербургских издания, в которых до I789 г. были опубликованы отрывки из «Персидских писем», и, что примечательно, два из них адресованы детской аудитории: «Повесть о народе несчастном от злодеяния и счастливом от добродетели» в книге «Детское чтение» (I779) и «Троглодиты, или Единое токмо исполнение добродетелей соделать может народ счастливым» в книге «Избранное чтение» (I786) [1; 6]. Чем обусловлено появление «вольтерьянского» романа на страницах детских книг и какие фрагменты романа обратили на себя внимание русских переводчиков?

Вторая половина XVIII в. - это период, когда детская книга начинает формироваться как самостоятельный вид литературы. Это обстоятельство обусловлено тем, что в этот период в Европе, в том числе в России, формулируются новые педагогические теории, благодаря которым фигура ребенка оказывается в кругу интересов просветителей и которые демонстрируют необходимость создания специальной литературы для детей [Іо; 7, с. 2I]. При том, что эти процессы захватывают все европейское пространство, в разных странах ситуация очень неоднородна. Пожалуй, наиболее солидную традицию детская книга имеет в Германии. В частности, передовую 
роль в распространении детской книги сыграли немецкие авторы Х.Ф. Вейсе (C.F. Weisse), И.Г. Кампе (J.H. Campe), Х.Г. Зальцман (C.G. Salzmann), И.Г. Шуммель (J.G. Schummel) и др. И хотя во второй половине XVIII в. детская литература еще находится на раннем этапе своего становления, перед ней ставятся очень серьезные задачи. Детская книга была призвана стать не чем иным, как инструментом воспитания, которое является одной из ключевых составляющих в системе координат эпохи Просвещения. В конечном счете именно от воспитания молодого поколения зависел успех проекта создания справедливого общества, свободного от предрассудков и живущего в соответствии с принципами Просвещения. В этом смысле задачи детской литературы согласуются с теми задачами, которые европейские просветители ставили перед литературой вообе, а именно воспитать «нового человека», разносторонне образованного и ответственного гражданина, который ставил бы интересы общества и государства выше личных интересов. Как справедливо отмечает С.А. Карайченцева, чтобы справиться с этими задачами, детская книга должна опираться на образцы и использовать воспитательный потенциал взрослой книги, прежде всего современной просветительской литературы [4].

В России начало целенаправленной политике в области распространения литературы для детей было положено в годы правления Екатерины II и в особенности в конце І780-х гг., когда выпуск детских книг приобретает регулярный характер. При этом процесс создания полноценного репертуара детской книги происходит с ориентацией на европейскую модель, как и в случае с литературой для взрослых. По примеру европейской литературы, в первоначальный круг детского чтения в России XVIII в. закономерно вводятся произведения современных европейских писателей, писавших для взрослой читательской аудитории: Вольтера, Ш.-Л. Монтескье, Ж.-Ф. де Сен-Ламбера, в особенности аббата Фенелона. Благодаря богатому воспитательному потенциалу его роман «Приключения Телемака» оказывается в числе наиболее популярных произведений среди грамотных детей в России конца XVIII - начала XIX вв. Очевидно, что труды просветителей вводились в круг чтения детей в сокращенном, адаптированном виде и, как правило, включались в сборники хрестоматийного типа. Многие из них известны под названием «Избранное чтение для детей». 


\section{История о Троглодитах: от Монтескье к Беркену}

Наряду с классиками детской литературы эпохи Просвещения (мадам Лепренс де Бомон, мадам Жанлис, Шарль Перро) симптоматична фигура французского детского писателя Арно Беркена (I749-I79I), познакомившего не одно поколение маленьких читателей во всей Европе с выдающимися образцами просветительской литературы. «Друг детей», как его стали называть после публикации одноименной книги («L`Ami des enfants», I782-I783), Беркен обращается к детской литературе в I770-е гг., когда получает назначение на должность наставника детей известного парижского издателя и книгопродавца Шарля-Жозефа Панкука. В этих обстоятельствах появляется книга «Lectures pour les enfants ou Choix de petits contes également propres à les amuser et à leur faire aimer la vertu». Книга была адресована детям в возрасте от трех до семи лет - таков был возраст подопечных Беркена. Впервые книга была опубликована в 1775 г., затем периодически переиздавалась, постепенно увеличиваясь в объеме. На сегодняшний день известно по крайней мере четыре издания - I775 г. (в I т.), I777 г. (в 2 т.), I78г г. (в 6 ч.) и I785 г. Последнее, парижское, издание насчитывает не менее 5 томов: в Национальной библиотеке Франции хранятся тома г и 5 [12, с. 304].

Следуя распространенной в XVIII - начале XIX вв. практике, Беркен охотно заимствует сюжеты для своих книг из других авторов. Как указывают биографы, писатель часто опирался на иностранные источники, прежде всего немецкие, а автором, которому он считал себя в наибольшей степени обязанным, называл Христиана Феликса Вейсе [І2, с. 30о]. Что касается «Lectures pour les enfants», отличительной чертой книги является наличие, помимо отрывков из разных современных авторов (Вольтер, Ш.-Л. Монтескье, Ж.-Ф. Мармонтель, Ж.-Ф. де Сен-Ламбер, П.-П.-Ф. Летурнер, С. Гесснер, Ф.-Т.-М. де Бакюляр д’Арно и др.), нескольких собственных произведений Беркена. В отношении заимствованных фрагментов автор справедливо ссылается на источник или по крайней мере указывает на то, что текст является свободным переводом или подражанием.

Из обширного наследия Монтескье Беркен заимствует для своей книги фрагмент романа «Персидские письма», известный как притча о Троглодитах. Этот эпизод фигурирует в романе в качестве своего рода вставной новеллы и выглядит как как самодовлеющий текст, не мотивированный ин- 
тригой. В романе содержится несколько подобных вставных новелл, которые встраиваются в ткань письма в виде поучительной истории или легенды. Каждая из них содержит определенную мораль, согласующуюся с тем фрагментом повествования, в который она помещена, и при этом содержит элементы, способствующие пониманию общего замысла романа. Но Беркен не случайно останавливает свой выбор именно на притче о Троглодитах (письма XI-XIV). Эта вставная новелла представляет особый интерес, поскольку в ней заключен богатый потенциал с точки зрения философской и политической мысли, и она имеет принципиальное значение в контексте философско-художественного наследия писателя.

Известно, что в соответствии с политической теорией Монтескье, подробно изложенной в трактате «О духе законов», различаются три типа правления: республиканский, монархический и деспотический. Основанием для различения этих форм правления выступает несколько критериев. Во-первых, Монтескье различает правление всех или некоторых (республика демократического типа и республика аристократического типа) и правление одного (монархия и деспотия). Во-вторых, в нормативном плане монархия опирается на установленные и неизменные законы, тогда как в деспотии один, не следуя никаким законам и установлениям, подчиняет всё своей воле и своим капризам. Республика опирается на закон и в этом смысле противостоит деспотии, поскольку обеспечивает свободу граждан право делать то, что дозволено законом [II]. Помимо этих объективных критериев, Монтескье вводит понятие принципа - некого субъективного компонента, который обеспечивает само существование и должное функционирование той или иной формы правления.

В основу монархии положен принцип чести, для деспотии таким принципом выступает страх, а для республики, которую Монтескье подразделяет на республику демократического типа и аристократического типа, соответственно добродетель и умеренность. По мысли Монтескье, именно республика демократического типа является наиболее совершенным из всех возможных государственных устройств. В республике люди живут согласно принципам справедливости, человечности и пр., они не подчиняются монарху, который стоит над ними, а все равны между собой. Богатство и роскошь не считаются благом, а личный интерес уступает интересу общественному. Именно эти качества являются отличительной чертой сооб- 
щества Троглодитов, которые направляли все свое внимание на то, чтобы воспитать своих детей в лучших правилах: «...в особенности старались они внушить детям, что выгода отдельных лиц всегда заключается в выгоде общественной, что желать отрешиться от последней - значит желать собственной погибели, что добродетель не должна быть нам в тягость, что отнюдь не следует считать ее постылой обязанностью и что справедливость по отношению к ближнему есть милосердие по отношению к нам самим» [5, с. 25]. Образ жизни Троглодитов - это и есть картина идеального, республиканского, устройства. В этом отношении историю Троглодитов закономерно рассматривать как апологию республиканского строя.

Впрочем, республика в глазах Монтескье - это скорее политическая утопия. И дело не только в том, что республика возможна только на небольших территориях, но прежде всего в том, что сами исторические обстоятельства неблагоприятны для этого типа государственного устройства. Развитие торговли и накопление богатств сделали невозможными равенство и воздержанность, которые были свойственны республикам Античности, таким образом, античная модель республики не применима к настоящему времени. Луи Альтуссер сказал о Монтескье: «Монтескье не верит в республику, и по весьма простой причине: время республик прошло» [8, с. 65].

Мысль о том, что республика невозможна или по крайней мере не может существовать в неизменном виде продолжительное время, содержится уже в притче о Троглодитах. Врожденная добродетель имела для Троглодитов такую же силу, какую для других народов имеет закон. Для того чтобы существовать и поддерживать порядок внутри сообщества, им достаточно было подчиняться своей добродетели. До тех пор, пока они придерживались этих принципов, Троглодиты были свободны. Но стоило им только задуматься о том, чтобы выбрать себе государя и впредь подчиняться уже не своей природной добродетели, а навязанным государем законам, - это означало добровольный отказ от свободы и неизбежный упадок установленного порядка. Эти опасения сформулированы в письме XIV: «Ваша добродетель начинает тяготить вас. В вашем теперешнем положении вам приходится, не имея вождя, быть добродетельными, хотите вы этого или нет: иначе вы не могли бы существовать <...>. Но это ярмо кажется вам слишком тяжелым: вы предпочитаете подчиниться государю и повиноваться его законам, - менее строгим, чем ваши нравы. Вы знаете, что тогда вам можно 
будет удовлетворять свое честолюбие, приобретать богатство и предаваться низкому вожделению и что вы не будете нуждаться в добродетели, лишь бы только избегали больших преступлений» [5, с. 29].

Помещая фрагменты «взрослой» литературы в книги, предназначенные для детской аудитории, Беркен руководствовался представлениями о том, что детское восприятие имеет свою специфику, и адаптировал тексты, исходя из этой специфики. В своем исследовании, посвященном Беркену, Ангус Мартин отмечает, что его книги отличаются легким стилем, что автору присущ талант рассказчика и понимание того, что́ может нравиться детям, которым чужды тяжеловесные диалоги и излишне морализаторские рассказы современников [І2, с. 308]. Так, притча о Троглодитах, которая легла в основу «Повести о народе несчастном от злодеяния и счастливом от добродетели» (у Беркена - «Histoire d'un peuple malheureux par le crime, et heureux par la vertu»), в романе «Персидские письма» изложена в нескольких письмах (XI-XIV). Беркен отказывается от эпистолярной формы и объединяет все письма в одну «повесть», сознательно выпустив последнее письмо. Кроме того, он убирает прямую речь (слова от лица Узбека, обращенные к его корреспонденту - Мирзе) и разбивает длинные фразы на несколько коротких, чтобы они легче воспринимались детьми. Помимо этих очевидных вмешательств в текст Монтескье, в целом текст Беркена полностью соответствует оригиналу. Можно отметить лишь незначительные лексико-грамматические правки (например, замена настоящего времени прошедшим или замена одного прилагательного другим прилагательным сходного значения), не искажающие смысл исходного текста. По понятным соображениям выпущен фрагмент фразы, где речь идет о «девственной стыдливости»: «c'est là que la pudeur virginale faisoit en rougissant un aveu surpris, mais bientôt confirmé par le consentement des pères» [I3, c. 3I]. Пepeход от повествования о «народе несчастном от злодеяния» (конец письма XI) к повествованию о «народе счастливом от добродетели» (начало письма XII) осуществляется путем пересказа нескольких фраз своими словами. Завершается рассказ словами, которые отсутствуют в романе: «et cédant à la vertu des Troglodytes, ils les laissèrent dès-lors jouir en paix de leur bonheur» [9, с. I45]. И в этом состоит принципиальное расхождение с текстом «Персидских писем», поскольку у Монтескье история о Троглодитах не завершается счастливым приобщением к добродетели. Напротив, в оставленном 
«за кадром» письме XIV содержится то основное содержание, которое писатель вкладывал в эту историю. Именно в этом письме раскрывается ее политический смысл, который был не нужен Беркену. Хотя своей задачей как автора книг для детей он видел в том числе и развитие ума маленьких читателей, но его книги содержат прежде всего нравоучительный материал и нацелены на воспитание в ребенке добрых душевных качеств.

\section{История о Троглодитах в русских детских изданиях}

Арно Беркен был хорошо известен за пределами Франции, в том числе в России. Его обильно переводили и подражали ему, многие его труды были помещены в русских переводах в первом русском журнале для детей «Детское чтение для сердца и разума» Н. Новикова (издавался с 1785 по I789 гг.), а затем и в других детских журналах первой половины XIX в. А еще ранее, в I779 г., в России вышла книга «Детское чтение, или Отборныя небольшия повести, удобныя увеселить детей и наставить их любить добродетель». Название в точности повторяет название книги Беркена и, в сущности, представляет собой не что иное, как ее перевод. Перевод принадлежит подпрапорщику лейб-гвардии Преображенского полка Капитону Бочарникову⿰ ${ }^{1}$ и является его первым литературным опытом. Как следует из посвящения Ф.М. Толстому, эта книга является учебным переводом, предпринятым по собственной инициативе автора в целях упражнения во французском языке: «Долг подчиненности, и желание засвидетельствовать пред Вашим Превосходительством мои упражнения, и мою нижайшую благодарность, обязывают меня первой мой труд посвятить высокими добродетелями славному имени Вашего Превосходительства» [I]. Очевидно, что свободное от служебных дел время Бочарников имел обыкновение отдавать литературным занятиям, во всяком случае, известно, что ему принадлежит еще несколько опубликованных работ, например, «Краткое описание российского торга» (I782) и «Описание нравов и употреблений древних народов» (1783).

В книгу Бочарникова вошло всего I2 текстов, а именно: фрагменты из Вольтера, Г. фон Клейста, С. Гесснера, Ж.-Ф. де Сен-Ламбера, П.-П.-Ф. Летурнера, Ш.-Л. Монтескье, Ж.-Ф. Мармонтеля, а также несколько фраг- 
ментов, источники которых не указаны. Нет однозначных указаний на то, какое издание книги Беркена - I775 или I777 г. - использовал Бочарников. В любом случае примечательно, что в его книгу вошла и «Повесть о народе несчастном от злодеяния, и счастливом от добродетели», которая, таким образом, является самым ранним опубликованным переводом романа «Персидские письма» на русский язык. Примечательно и то, что в основу перевода лег не оригинальный текст Монтескье, а именно адаптированная версия. О том, что книга в целом является именно переводом книги Беркена, а не самостоятельной подборкой, говорит не только факт абсолютного тождества названий как самих сборников, так и вошедших в них фрагментов, но и текстуальное тождество.

Иначе обстоит дело с книгой «Избранное чтение, или Собрание чувствительных и к внушению добродетели споспешествующих повестей», изданной Иваном Чашниковым в I786 г. В отличие от «Детского чтения» Бочарникова, «Избранное чтение» представляет собой самостоятельную подборку текстов, выполненную самим переводчиком, хотя эта книга также является пробой пера молодого автора и написана, как следует из посвящения И.И. Михельсону, в «свободные от должности» часы: «Служа под покровительством Вашего Превосходительства, свободныя от должности моей часы употребил я на сей мой маловажный труд, и за долг счел посвятить оный имяни вашему ведая довольно оказываемое вами ободрение к упражняющимся в учености» [6]. Как и Бочарников, Иван Александрович Чашников (I772-I8г8) принадлежал к военному сословию - служил в лейб-гвардии Конном полку, а литературой и переводами с французского языка занимался в целях самообразования.

В книге Чашникова содержится 8 неравнозначных по объему и характеру повествования фрагментов - рассказов и анекдотов из разных, по всей видимости, источников. Примечательно, что ссылки на источники не приводятся. Это обстоятельство дало повод к появлению гипотезы о том, что эти тексты не являются собственно переводами, а оригинальными сочинениями самого Чашникова [2]. Исключение составляет лишь один фрагмент, а именно «Троглодиты, или Единое токмо исполнение добродетелей соделать может народ счастливым», о котором сказано: «переведено из “Персидских писем” сочинения Г. Монтескию». Все фрагменты, вошедшие в сборник, подчинены общей идее, заданной в заглавии: обращаясь не 
столько к уму, сколько к чувствам маленьких читателей, автор преследовал цель сформировать у них понятие о необходимости сострадания, добродетели, заботы каждого человека об общественном благе как залоге личного счастья.

\section{Как переводили Монтескье на русский язык?}

Сопоставляя переводы, выполненные Бочарниковым и Чашниковым, однозначно можно сказать, что первый заметно уступает второму и не обладает высокой художественной ценностью. Очевидно, что переводчик стремился соответствовать источнику с максимальной точностью, в частности, сохранил форму «повести», которую придал этой истории Беркен. Более того, он попытался приблизить к французскому оригиналу даже синтаксис и обороты речи, отчего перевод получился буквальным, слишком громоздким и в целом производит впечатление перевода ученического. Приведем несколько конкретных примеров. Переводя фрагмент, в котором описывается жестокость и безнравственность первых Троглодитов, Бочарников пишет: «Все частные [= «tous les particuliers»] согласились, чтоб всякой бдел о своих выгодах без всякаго внимания на выгоды другаго» [г, с. 47]. Тот же самый фрагмент у Чашникова выглядит так: «Все согласились, никого более не слушаться, чтоб всякой старался единственно о своих пользах, не заботясь о других» [6, с. 92]. Далее Бочарников описывает жестокие нравы Троглодитов: «Половина народа вопили во второй раз глад [= «cria une seconde fois famine»]; но сии жалкие встретали (sic) столь же жестоких людей, таковы они были сами» [I, c. 48]. У Чашникова: «Одна половина народа вторично претерпевала голод, но сии нещастные нашли людей столь же жестокими, каковы они и сами были» [6, с. 94]. Или: «Я имею возделывать свое поле [= «j'ai mon champ à labourer»], я не намерен может быть употреблять моего времени на разрешение распрей ваших и утруждаться вашими делами, пренебрегая чрез то мои» [I, c. 48], в то время как Чашников пишет: «Я должен обработывать (sic) свою землю; я не хочу тратить времени на решение ваших споров, стараться о ваших делах и между тем оставлять свои собственныя»[6, с. 95], и т. д.

При том, что перевод Чашникова тоже точен, его язык более естествен, а синтаксис характерен для русского языка. Переводчик допускает определенную свободу в выборе лексических средств, когда того требует 
логика языка и здравый смысл, но делает это очень бережно по отношению к оригиналу. Примечательно, что Чашников даже находит способ сохранить без искажений смысла фрагмент, выпущенный Беркеном (и Бочарниковым) из соображений необходимости адаптировать текст для детской аудитории: «там стыдливая девица красная делала признание нечаянное, но скоро подтвержденное согласием отцов» [6, с. Iо4] (ср.: «c'est là que la pudeur virginale faisoit en rougissant un aveu surpris, mais bientôt confirmé par le consentement des pères»).

В целом перевод Чашникова отличается полнотой, отсутствием купюр, случайных или намеренных. Принципиально и то, что переводчик использовал первоисточник - оригинальный текст Монтескье, а не сокращенный «пересказ». Так, в отличие от своих предшественников Беркена и Бочарникова, он сохранил эпистолярную форму, нумерацию писем, указание адресата и датировку писем. При том, что непосредственно повествование о Троглодитах начинается в письме XI, Чашников захватывает также и предыдущее письмо, в котором Мирза обращается к своему другу Узбеку с просьбой разъяснить ему, что́ Узбек думает по поводу такого вопроса: бывают ли люди более счастливы от увеселений или от удовлетворения добродетели? В этом письме, которое является своего рода преамбулой к истории о Троглодитах, переводчик выпустил лишь первую строчку. Даже письмо XIV, в котором содержится политическая мораль истории и которое отсутствует у Беркена и Бочарникова, переведено полностью.

Заметим, что на момент публикации «Избранного чтения» в 1786 г. Чашникову было всего четырнадцать лет. Очевидно, что молодому автору были близки положения, раскрытые в этой книге, а именно пропаганда идеи просвещенного монарха и справедливого общества, основанного на принципах первенства закона и всеобщего блага. Во всяком случае схожие проблемы затронуты и в другой переведенной им в том же I786 г. книге «Рассуждение о великих людях» Фридриха Августа, герцога Брауншвейг-Эльского.

Так почему же именно история о Троглодитах привлекает внимание детских писателей? В чем состоит ее польза для детей? Хотя для перевода использован материал взрослой просветительской литературы, мораль это- 
го конкретного эпизода как нельзя лучше соотносится с представлениями эпохи о воспитании детей. А именно воспитательный потенциал притчи заключается в том, что она демонстрирует преимущества такой общественной организации, при которой личные интересы уступают интересам общественным, где счастье одного человека невозможно без счастья других.

Учитывая тот факт, что притча о Троглодитах дается вне контекста романа, то очевидно, что в переводах утрачен политический смысл истории в том объеме и с той глубиной, который она имела у Монтескье (речь идет о стремлении установить связь между понятием добродетели и республиканским строем). История Троглодитов в обоих русских изданиях преподносится прежде всего как нравоучительный рассказ, призывающий чтить добродетель.

При относительной тождественности авторских намерений переводы не равнозначны. Далеко не последнюю роль в этом сыграл тот факт, что в их основу положены различные источники. Перевод Бочарникова выполнен на основании текста-посредника, в роли которого выступила книга Арно Беркена и который, как всякий адаптированный материал, несет на себе отпечаток авторского видения. В отличие от своего предшественника, Чашников опирается исключительно на оригинальный текст романа «Персидские письма». Как следствие, в первом случае политическая составляющая истории остается вне поля зрения переводчика, во втором она присутствует, хотя и не является доминирующей. Оценивая собственно качество переводов, можно говорить о том, что перевод Ивана Чашникова отличается не только полнотой и соответствием оригиналу, но и более высокими художественными качествами. Этот текст, хоть и принадлежит к числу самых ранних работ молодого автора, тем не менее свидетельствует о довольно высоком уровне владения словом, зрелости и самостоятельности Чашникова как переводчика.

То обстоятельство, что обе книги являются переводными, представляется нормой детской и юношеской литературы, которая с момента ее зарождения, в эпоху Просвещения, не перестает быть объектом «обмена» между странами Европы. Переводчики охотно используют сюжеты иноязычных литератур, принимая во внимание специфику детского мышления, свободного от национальных предрассудков и ориентированного прежде всего на восприятие содержания книги, а не на ее происхождение. В этом 
смысле «Детское чтение» Бочарникова и «Избранное чтение» Чашникова являют собой классические примеры литературы для детей конца XVIII в. При этом, хотя ни одна из них не имела значительного распространения, обе эти книги представляют известный интерес в более широком контексте русско-французских литературных связей. Их авторам принадлежит заслуга первыми открыть для русского читателя творчество таких писателей, как Ш.-Л. Монтескье, которым в свою очередь предстояло сыграть выдающуюся роль в формировании русского Просвещения. 


\section{Список литературы}

I Бочарников К. Детское чтение или Отборныя небольшия повести, удобные увеселить детей и наставить их любить добродетель. Переведены с францускаго языка Лейбгвардии Преображенскаго полку подпрапорщиком Капитоном Бачарниковым. СПб.: Тип. Арт. и инж. кадет. корпуса, I779. 82 с.

2 Выдрин И. Загадочный Иван Чашников // В мире книг. I974. № I2. С. 87.

3 Дмитриев В.Г. «Персидские письма» в России // Дмитриев В.Г. По стране литературии: Этюды. М.: Московский рабочий, І987. С. Іо7-ІІІ.

4 Карайченщева С.А. Русская детская книга XVIII-XX вв.: (очерки эволюции репертуара. І7І7-І990 гг.). М.: Изд-во МГУП, 2006. 292 с.

5 Монтескье Ш.-Л. Персидские письма // Французский фривольный роман / пер. с фр., прим. А. Бондарева, А. Михайлова, В. Жирмунского. М.: ЭКСМО, 2008. C. 5-252. Чашников И.А. Избранное чтение, или Собрание чувствительных и к внушению добродетели споспешествующих повестей. СПб.: Тип. Вильковскаго и Галченкова, І786. І23 с. Чехов Н.В. Очерки истории русской детской литературы (I750-I855) // Материалы по истории русской детской литературы (I750-I855) / под ред. А.К. Покровской и Н.В. Чехова. М.: ИМВР, І927. Вып. І. С. І7-88. Althusser L. Montesquieu, la politique et l'histoire . Paris: PUF, I959. I20 p.

9 Berquin A. Lectures pour les enfants, ou Choix de petits contes également propres à les amuser et à leur faire aimer la vertu. Nouv. éd. corrigée et augmentée, tome premier. Genève: chez Isac Bardin libraire, I780. 236 p. Colin M. La littérature d'enfance et de jeunesse en France et en Italie au XIXe siècle. Traductions et influences. Paris: Université de la Sorbonne nouvelle, I992. 89 p. Keller A. République // Dictionnaire Montesquieu [en ligne], sous la direction de Catherine Volpilhac-Auger, ENS de Lyon, septembre 20I3. URL: http://dictionnairemontesquieu.ens-lyon.fr/fr/article/I377636396/fr/ (дата обращения: І2.12.2018) Martin A. Notes sur L'Ami des enfants de Berquin et la littérature enfantine en France aux alentours de I780, Dix-huitième Siècle, № 6, I974. Lumières et Révolution, pp. 299-308.

I3 Montesquieu Ch.-L. de. Lettres persanes. 2 vol. Paris: Alphonse Lemerre éditeur, I873.

\section{References}

I Bocharnikov K. Detskoe chtenie ili Otbornyia nebol'shiia povesti, udobnye uveselit' detei i nastavit' ikh liubit' dobrodetel' [Reading for children, or Selected tales appropriate both for amusing them and make them love the virtue]. Translated from French by Leibgvardii Preobrazhenskago polku podpraporshchikom Kapitonom Bacharnikovym. St. Petersburg, Tip. Art. i inzh. kadet. Korpusa Publ., I779. 82 p. (In Russ.) 
Vydrin I. Zagadochnyi Ivan Chashnikov [Mysterious Ivan Chashikov]. V mire knig, I974, no I2, pp. 87. (In Russ.)

Dmitriev V.G. "Persidskie pis'ma" v Rossii [Persian Letters in Russia]. Dmitriev V.G. Po strane literaturii: Etiudy [Across the country of literature: essays]. Moscow, Moskovskii rabochii Publ., 1987, pp. I07-III. (In Russ.)

Karaichentseva S.A. Russkaia detskaia kniga XVIII-XX vv.: (ocherki evoliutsii repertuara. $1717^{-1990} \mathrm{gg}$.) [Russian children's book of the $\mathrm{I}^{\text {th }}-2 \mathrm{O}^{\text {th }}$ centuries: (essays on the evolution of literary production. I7I7-I990)]. Moscow, Izd-vo MGUP, 2006. 292 p. (In Russ.)

Montesk'e Sh.-L. Persidskie pis'ma [Persian letters]. Frantsuzskii frivol'nyi roman [French frivolous novel], transl. from fr. French, ref. by A. Bondarev, A. Mikhailov, V. Zhirmunskii. Moscow, EKSMO Publ., 2008, pp. 5-252. (In Russ.)

Chashnikov I.A. Izbrannoe chtenie, ili Sobranie chuvstvitel'nykh $i k$ vnusheniiu dobrodeteli spospeshestvuiushchikh povestei [Selected reading, or Collection of sentimental tales encouraging virtue]. St. Petersburg, Tip. Vil'kovskago i Galchenkova Publ., I786. I23 p. (In Russ.)

Chekhov N.V. Ocherki istorii russkoi detskoi literatury (I750-I855) [Essays on the history of Russian children's literature (1750-1855)]. Materialy po istorii russkoi detskoi literatury (I750-I855) [Materials on the history of Russian children's literature (I750-I855)], eds. A.K. Pokrovskaia and N.V. Chekhov. Moscow, IMVR Publ., I927, issue I, pp. I7-88. (In Russ.)

Althusser L. Montesquieu, la politique et l'histoire. Paris, PUF, I959. I20 p. (In French)

Berquin A. Lectures pour les enfants, ou Choix de petits contes également propres à les amuser et à leur faire aimer la vertu. Nouv. éd. corrigée et augmentée, tome premier. Genève, chez Isac Bardin libraire, I780. 236 p. (In French) Colin M. La littérature d'enfance et de jeunesse en France et en Italie au XIXe siècle. Traductions et influences. Paris, Université de la Sorbonne nouvelle, I992. 89 p. (In French)

II Keller A. République. Dictionnaire Montesquieu [en ligne], sous la direction de Catherine Volpilhac-Auger, ENS de Lyon, septembre 20I3. Available at: http:// dictionnaire-montesquieu.ens-lyon.fr/fr/article/1377636396/fr/ (Accessed I2 December 2018) (In French)

2 Martin A. Notes sur L 'Ami des enfants de Berquin et la littérature enfantine en France aux alentours de I780, Dix-huitième Siècle, № 6, 1974. Lumières et Révolution, pp. 299-308. (In French)

Montesquieu Ch.-L. de. Lettres persanes. 2 vol. Paris Alphonse Lemerre éditeur, I873. (In French) 